\title{
Silver nanoparticles: mechanism of antimicrobial action, synthesis, medical applications, and toxicity effects
}

\author{
Sukumaran Prabhu* and Eldho K Poulose
}

\begin{abstract}
Silver nanoparticles are nanoparticles of silver which are in the range of 1 and $100 \mathrm{~nm}$ in size. Silver nanoparticles have unique properties which help in molecular diagnostics, in therapies, as well as in devices that are used in several medical procedures. The major methods used for silver nanoparticle synthesis are the physical and chemical methods. The problem with the chemical and physical methods is that the synthesis is expensive and can also have toxic substances absorbed onto them. To overcome this, the biological method provides a feasible alternative. The major biological systems involved in this are bacteria, fungi, and plant extracts. The major applications of silver nanoparticles in the medical field include diagnostic applications and therapeutic applications. In most of the therapeutic applications, it is the antimicrobial property that is being majorly explored, though the anti-inflammatory property has its fair share of applications. Though silver nanoparticles are rampantly used in many medical procedures and devices as well as in various biological fields, they have their drawbacks due to nanotoxicity. This review provides a comprehensive view on the mechanism of action, production, applications in the medical field, and the health and environmental concerns that are allegedly caused due to these nanoparticles. The focus is on effective and efficient synthesis of silver nanoparticles while exploring their various prospective applications besides trying to understand the current scenario in the debates on the toxicity concerns these nanoparticles pose.
\end{abstract}

Keywords: Silver nanoparticle, Antimicrobial action, Synthesis, Medical applications, Silver nanotoxicity

\section{Review} Introduction

The medical properties of silver have been known for over 2,000 years. Since the nineteenth century, silver-based compounds have been used in many antimicrobial applications. Nanoparticles have been known to be used for numerous physical, biological, and pharmaceutical applications. Silver nanoparticles are being used as antimicrobial agents in many public places such as railway stations and elevators in China, and they are said to show good antimicrobial action.

It is a well-known fact that silver ions and silver-based compounds are highly toxic to microorganisms which include 16 major species of bacteria [1,2]. This aspect of silver makes it an excellent choice for multiple roles in the

\footnotetext{
* Correspondence: sprabhu@svce.ac.in

Department of Biotechnology, Sri Venkateswara College of Engineering, Sriperumbudur, Tamil Nadu 602105, India
}

medical field. Silver is generally used in the nitrate form to induce antimicrobial effect, but when silver nanoparticles are used, there is a huge increase in the surface area available for the microbe to be exposed to. Though silver nanoparticles find use in many antibacterial applications, the action of this metal on microbes is not fully known. It has been hypothesized that silver nanoparticles can cause cell lysis or inhibit cell transduction. There are various mechanisms involved in cell lysis and growth inhibition.

There are many ways depicted in various literatures to synthesize silver nanoparticles. These include physical, chemical, and biological methods. The physical and chemical methods are numerous in number, and many of these methods are expensive or use toxic substances which are major factors that make them 'not so favored' methods of synthesis. An alternate, feasible method to synthesize silver nanoparticles is to employ biological methods of using microbes and plants. 
Silver nanoparticles find use in many fields, and the major applications include their use as catalysts, as optical sensors of zeptomole $\left(10^{-21}\right)$ concentration, in textile engineering, in electronics, in optics, and most importantly in the medical field as a bactericidal and as a therapeutic agent. Silver ions are used in the formulation of dental resin composites; in coatings of medical devices; as a bactericidal coating in water filters; as an antimicrobial agent in air sanitizer sprays, pillows, respirators, socks, wet wipes, detergents, soaps, shampoos, toothpastes, washing machines, and many other consumer products; as bone cement; and in many wound dressings to name a few. Though there are various benefits of silver nanoparticles, there is also the problem of nanotoxicity of silver. There are various literatures that suggest that the nanoparticles can cause various environmental and health problems, though there is a need for more studies to be conducted to conclude that there is a real problem with silver nanoparticles.

This review provides an idea of the antimicrobial properties silver possesses as a nanoparticle, the various methods employed to synthesize silver nanoparticles, and an overview of their applications in the medical field and also discusses the toxicity of silver nanoparticles. The focus is on the characteristics of silver nanoparticles which make them excellent candidates for use in the medical field besides delving into the unique ability of certain biological systems to synthesize silver nanoparticles and also looks at the chances of these particles to induce toxicity in humans and the environment as a whole.

\section{Action of silver nanoparticles on microbes}

The exact mechanism which silver nanoparticles employ to cause antimicrobial effect is not clearly known and is a debated topic. There are however various theories on the action of silver nanoparticles on microbes to cause the microbicidal effect.

Silver nanoparticles have the ability to anchor to the bacterial cell wall and subsequently penetrate it, thereby causing structural changes in the cell membrane like the permeability of the cell membrane and death of the cell. There is formation of 'pits' on the cell surface, and there is accumulation of the nanoparticles on the cell surface [3]. The formation of free radicals by the silver nanoparticles may be considered to be another mechanism by which the cells die. There have been electron spin resonance spectroscopy studies that suggested that there is formation of free radicals by the silver nanoparticles when in contact with the bacteria, and these free radicals have the ability to damage the cell membrane and make it porous which can ultimately lead to cell death $[4,5]$.

It has also been proposed that there can be release of silver ions by the nanoparticles [6], and these ions can interact with the thiol groups of many vital enzymes and inactivate them [7]. The bacterial cells in contact with silver take in silver ions, which inhibit several functions in the cell and damage the cells. Then, there is the generation of reactive oxygen species, which are produced possibly through the inhibition of a respiratory enzyme by silver ions and attack the cell itself. Silver is a soft acid, and there is a natural tendency of an acid to react with a base, in this case, a soft acid to react with a soft base [8]. The cells are majorly made up of sulfur and phosphorus which are soft bases. The action of these nanoparticles on the cell can cause the reaction to take place and subsequently lead to cell death. Another fact is that the DNA has sulfur and phosphorus as its major components; the nanoparticles can act on these soft bases and destroy the DNA which would definitely lead to cell death [9]. The interaction of the silver nanoparticles with the sulfur and phosphorus of the DNA can lead to problems in the DNA replication of the bacteria and thus terminate the microbes.

It has also been found that the nanoparticles can modulate the signal transduction in bacteria. It is a wellestablished fact that phosphorylation of protein substrates in bacteria influences bacterial signal transduction. Dephosphorylation is noted only in the tyrosine residues of gram-negative bacteria. The phosphotyrosine profile of bacterial peptides is altered by the nanoparticles. It was found that the nanoparticles dephosphorylate the peptide substrates on tyrosine residues, which leads to signal transduction inhibition and thus the stoppage of growth. It is however necessary to understand that further research is required on the topic to thoroughly establish the claims [10] (Figure 1).

\section{Chemical and physical syntheses of silver nanoparticles}

The production of nanoparticles majorly involves physical and chemical processes. Silver nanomaterials can be obtained by both the so-called 'top-down' and 'bottom-up' methods. The top-down method involves the mechanical grinding of bulk metals and subsequent stabilization of the resulting nanosized metal particles by the addition of colloidal protecting agents $[11,12]$. The bottom-up methods, on the other hand, include reduction of metals, electrochemical methods, and sonodecomposition.

There are various physical and chemical methods, of which the simplest method involves the chemical method of reduction of the metal salt $\mathrm{AgBF}_{4}$ by $\mathrm{NaBH}_{4}$ in water. The obtained nanoparticles with the size range of 3 to $40 \mathrm{~nm}$ are characterized by transmission electron microscopy (TEM) and UV-visible (UV-vis) absorption spectroscopy to evaluate their quality [13]. There is the electrochemical method which involves the electroreduction of $\mathrm{AgNO}_{3}$ in aqueous solution in the presence of polyethylene glycol. The nanoparticles thus produced are characterized by TEM, X-ray diffraction, and UV-vis absorption spectroscopy and are $10 \mathrm{~nm}$ in diameter [14]. 


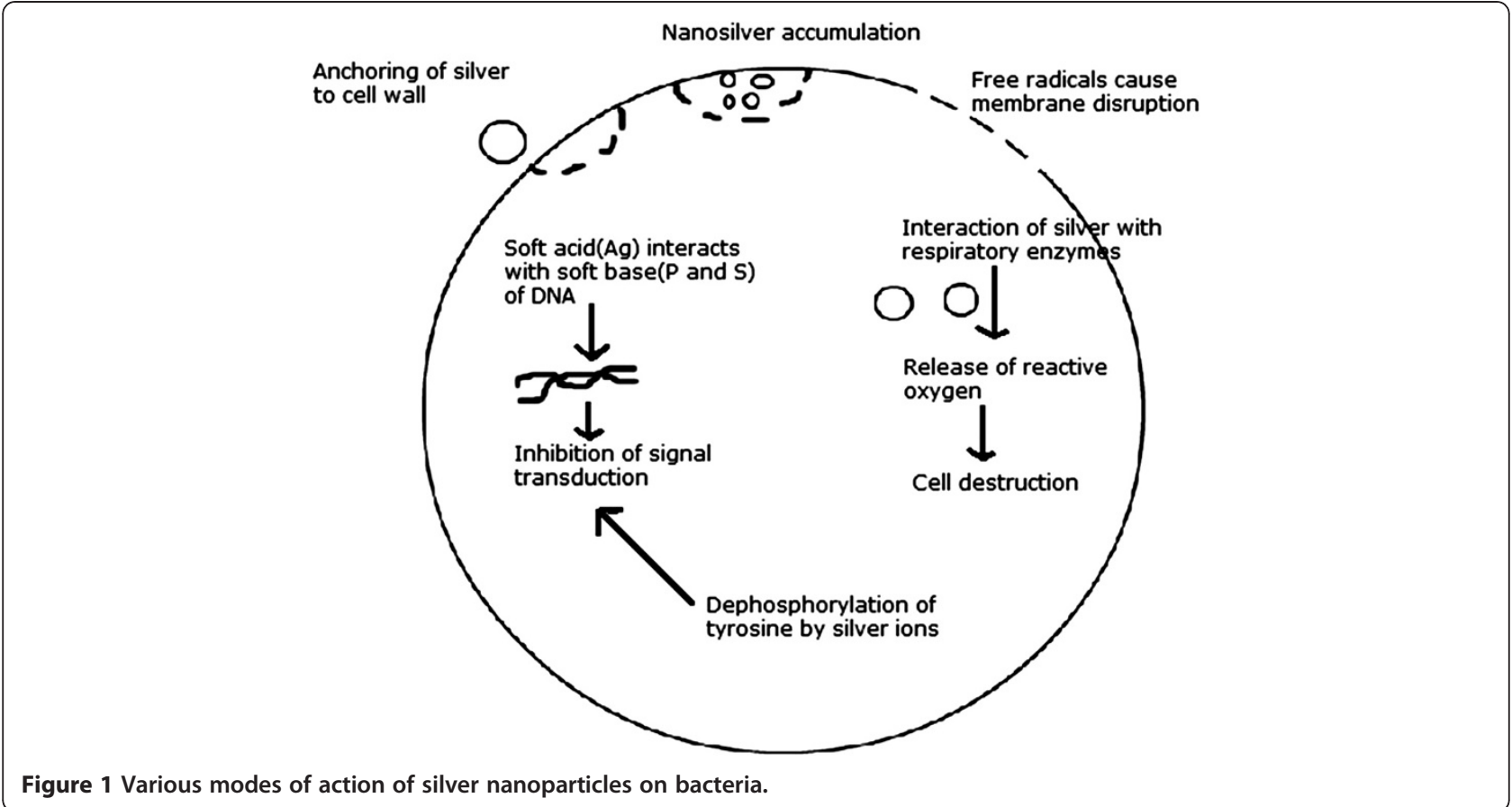

Sonodecomposition, to yield silver nanoparticles, involves the usage of ultrasonic waves to induce cavitation, a phenomenon whereby the passage of ultrasonic waves through an aqueous solution yields microscopic bubbles that expand and ultimately burst. The synthesis of silver nanoparticles involves sonochemical reduction of an aqueous silver nitrate solution in an atmosphere of argon-hydrogen. The silver nanoparticles are then characterized by TEM, X-ray diffraction, absorption spectroscopy, differential scanning calorimetry, and EPR spectroscopy and are found to be $20 \mathrm{~nm}$ in diameter. The mechanism of the sonochemical reduction occurs due to the generation of hydrogen radicals during the sonication process [15].

Nanoparticles are also synthesized within aqueous foams as a template. The method involves electrostatically complexing silver ions with an anionic surfactant aerosol in highly stable liquid foam. The foam is subsequently drained off and reduced by introducing sodium borohydride. These silver nanoparticles are extremely stable in solution, suggesting that the aerosol stabilizes them. This method gave nanoparticles of 5 to $40 \mathrm{~nm}$ in diameter [16].

A microwave synthesis of silver nanoparticles involves the reduction of silver nanoparticles using variable frequency microwave radiation as against the conventional heating method. The method yields a faster reaction and gives a higher concentration of silver nanoparticles with the same temperature and exposure. It was also found that the higher the concentration of silver nitrate used, the longer the reaction time was and the higher the temperature, the bigger the particle size was, while the higher the poly( $N$-vinylpyrrolidone) concentration, the smaller the silver particle size was (between 15 and 25 nm) [17].

There are also many more techniques of synthesizing silver nanoparticles, such as thermal decomposition in organic solvents [18], chemical and photoreduction in reverse micelles $[19,20]$, spark discharge [21], and cryochemical synthesis [22] which yielded nanoparticles between the ranges of 5 to $80 \mathrm{~nm}$ in diameter.

\section{Biological synthesis of silver nanoparticles}

The problem with most of the chemical and physical methods of nanosilver production is that they are extremely expensive and also involve the use of toxic, hazardous chemicals, which may pose potential environmental and biological risks. It is an unavoidable fact that the silver nanoparticles synthesized have to be handled by humans and must be available at cheaper rates for their effective utilization; thus, there is a need for an environmentally and economically feasible way to synthesize these nanoparticles. The quest for such a method has led to the need for biomimetic production of silver nanoparticles whereby biological methods are used to synthesize the silver nanoparticles. The growing need to develop environmentally friendly and economically feasible technologies for material synthesis led to the search for biomimetic methods of synthesis [23]. In most cases, the chemical synthesis methods lead to some chemically toxic substances being absorbed on the surface and can hinder their usage in medical applications [24]. There are three major sources of synthesizing 
silver nanoparticles: bacteria, fungi, and plant extracts. Biosynthesis of silver nanoparticles is a bottom-up approach that mostly involves reduction/oxidation reactions. It is majorly the microbial enzymes or the plant phytochemicals with antioxidant or reducing properties that act on the respective compounds and give the desired nanoparticles. The three major components involved in the preparation of nanoparticles using biological methods are the solvent medium for synthesis, the environmentally friendly reducing agent, and a nontoxic stabilizing agent.

\section{Silver-synthesizing bacteria}

The first evidence of bacteria synthesizing silver nanoparticles was established using the Pseudomonas stutzeri AG259 strain that was isolated from silver mine [25]. There are some microorganisms that can survive metal ion concentrations and can also grow under those conditions, and this phenomenon is due to their resistance to that metal. The mechanisms involved in the resistance are efflux systems, alteration of solubility and toxicity via reduction or oxidation, biosorption, bioaccumulation, extracellular complex formation or precipitation of metals, and lack of specific metal transport systems [26]. There is also another aspect that though these organisms can grow at lower concentrations, their exposure to higher concentrations of metal ions can induce toxicity.

The most widely accepted mechanism of silver biosynthesis is the presence of the nitrate reductase enzyme. The enzyme converts nitrate into nitrite. In in vitro synthesis of silver using bacteria, the presence of alpha-nicotinamide adenine dinucleotide phosphate reduced form (NADPH)dependent nitrate reductase would remove the downstream processing step that is required in other cases. During the reduction, nitrate is converted into nitrite and the electron is transferred to the silver ion; hence, the silver ion is reduced to silver $\left(\mathrm{Ag}^{+}\right.$to $\left.\mathrm{Ag}^{0}\right)$. This has been said to be observed in Bacillus licheniformis which is known to secrete NADPH and NADPH-dependent enzymes like nitrate reductase that effectively converts $\mathrm{Ag}^{+}$to $\mathrm{Ag}^{0}$ [27]. The mechanism was further confirmed by using purified nitrate reductase from Fusarium oxysporum and silver nitrate along with NADPH in a test tube, and the change in the color of the reaction mixture to brown and further analysis confirmed that silver nanoparticles were obtained [28]. There are also cases which indicate that there are other ways to biosynthesize silver nanoparticles without the presence of enzymes. It was found that dried cells of Lactobacillus sp. A09 can reduce silver ions by the interaction of the silver ions with the groups on the microbial cell wall [29] (Table 1).

\section{Silver-synthesizing fungi}

When in comparison with bacteria, fungi can produce larger amounts of nanoparticles because they can secrete larger amounts of proteins which directly translate to higher productivity of nanoparticles [40]. The mechanism of silver nanoparticle production by fungi is said to follow the following steps: trapping of $\mathrm{Ag}^{+}$ions at the surface of the fungal cells and the subsequent reduction of the silver ions by the enzymes present in the fungal system [41]. The extracellular enzymes like naphthoquinones and anthraquinones are said to facilitate the reduction. Considering the example of F. oxysporum, it is believed that the NADPH-dependent nitrate reductase and a shuttle quinine extracellular process are responsible for nanoparticle formation [42]. Though the exact mechanism involved in silver nanoparticle production by fungi is not fully deciphered, it is believed that the abovementioned phenomenon is responsible for the process. A major drawback of using microbes to synthesize silver nanoparticles is that it is a very slow process when in comparison with plant extracts. Hence, the use of plant extracts to synthesize silver nanoparticles becomes an option that is feasible (Table 2).

\section{Silver-synthesizing plants}

The major advantage of using plant extracts for silver nanoparticle synthesis is that they are easily available, safe, and nontoxic in most cases, have a broad variety of metabolites that can aid in the reduction of silver ions, and are quicker than microbes in the synthesis.

The main mechanism considered for the process is plant-assisted reduction due to phytochemicals. The main phytochemicals involved are terpenoids, flavones, ketones, aldehydes, amides, and carboxylic acids. Flavones, organic acids, and quinones are water-soluble phytochemicals that are responsible for the immediate reduction of the ions. Studies have revealed that xerophytes contain emodin, an anthraquinone that undergoes tautomerization, leading to the formation of the silver nanoparticles. In the case of mesophytes, it was found that they contain three types of benzoquinones: cyperoquinone, dietchequinone, and remirin. It was suggested that the phytochemicals are involved directly in the reduction of the ions and formation of silver nanoparticles [53]. Though the exact mechanism involved in each plant varies as the phytochemical involved varies, the major mechanism involved is the reduction of the ions (Table 3).

\section{Medical applications of silver nanoparticles}

Silver nanoparticles, due to their unique properties, find use in many day-to-day applications in human life. A few examples include their addition in house cleaning chemicals, in fabric cleaners, as antireflection coatings, to improve the transfer of heat from collectors of solar energy to their fuel tanks, to produce high-performance delicate electronics, and in hundreds of other applications. Though 
Table 1 Silver-synthesizing bacteria and the synthesized particle size

\begin{tabular}{|c|c|c|c|}
\hline Serial number & Organism & Particle size (nm) & Reference \\
\hline 1 & P. stutzeri AG259 & 200 & {$[30]$} \\
\hline 2 & Bacillus megaterium & 46.9 & [31] \\
\hline 3 & Plectonema boryanum & 1 to 200 & [32] \\
\hline 4 & Enterobacter cloacae & 50 to 100 & [33] \\
\hline 5 & Escherichia coli & 5 to 25 & [34] \\
\hline 6 & B. licheniformis & 50 & [35] \\
\hline 7 & Lactobacillus fermentum & 11.2 & [36] \\
\hline 8 & Klebsiella pneumonia & 50 & {$[37]$} \\
\hline 9 & Proteus mirabilis & 10 to 20 & [38] \\
\hline 10 & Brevibacterium casei & 50 & [39] \\
\hline
\end{tabular}

all these are important applications of silver nanoparticles, perhaps their need is most desired in the medical field.

The general aspect of nanoparticles is that the small size of nanoparticles provides for a larger surface area for the particle and hence increases the effect. The nanosize of the particles also increases the penetration potential of the silver particles, hence again aiding in better utilization of the metal properties. Based on the size factor alone, nanoparticles have the ability to penetrate the circulatory system and translocate even the blood-brain barrier in the human system.

The antimicrobial nature of silver nanoparticles is the most exploited nature of silver nanoparticles in the medical field, though the anti-inflammatory nature is also considered immensely useful in the medical field. Initial studies have suggested that the acceleration of wound healing in the presence of nanoparticles is due to the reduction of local matrix metalloproteinase (MMP) activity and the increase in neutrophil apoptosis within the wound. It has been suggested that the MMP can induce inflammation and hence cause non-healing wounds [64]. A reduction in the levels of pro-inflammatory cytokines was also demonstrated in a mouse model with burn injury when silver nanoparticles were introduced [65]. It was also found that silver nanoparticles can inhibit the activities of interferon gamma and tumor necrosis factor alpha which are involved in inflammation [66]. Though these studies prove that silver nanoparticles are involved in the anti-inflammatory effects, the exact, precise mechanism of action remains to be determined. The anti-inflammatory effects induced by nanosilver however make it an excellent candidate for use as antiinflammatory agents that can be used for various therapies.

Dr. Robert Burrell is said to have developed the world's first nanosilver-based wound dressing in 1995. He developed Acticoat that speeds up the healing process and removes scars if any [67]. Acticoat has become the final word when it comes to wound dressings; however, there are numerous other players in the same field. It is sold worldwide by Smith \& Nephew plc. Nanosilver is effective due to the fact that it has a much better effect on the bacteria that tend to infect the wound and due to the fact that it can easily penetrate the wound through the body fluids. The most prominent players in silver-based wound healing are Acticoat 7, Acticoat Moisture Control, Acticoat Absorbent, Silvercel, Aquacel Ag, Contreet F, Urgotol SSD, and Actisorb.

In July 2010, there were reports that scientists at the University of Bath and the burns team of the South West

Table 2 Silver-synthesizing fungi and the synthesized particle size

\begin{tabular}{|c|c|c|c|}
\hline Serial number & Organism & Particle size (nm) & Reference \\
\hline 1 & Verticillium sp. & 25 & {$[43]$} \\
\hline 2 & Phoma sp. 3.2883 & 70 & [44] \\
\hline 3 & F. oxysporum & 20 to 50 & {$[45]$} \\
\hline 4 & Phanerochaete chrysosporium & 100 & {$[46]$} \\
\hline 5 & Aspergillus fumigatus & 5 to 25 & [47] \\
\hline 6 & Aspergillus flavus & 7 to 10 & [48] \\
\hline 7 & Fusarium semitectum & 10 to 60 & [49] \\
\hline 8 & Coriolus versicolor & 350 to 600 & {$[50]$} \\
\hline 9 & Fusarium solani & 5 to 35 & [51] \\
\hline 10 & Aspergillus clavatus & 10 to 25 & {$[52]$} \\
\hline
\end{tabular}


Table 3 Silver-synthesizing plants and the synthesized particle size

\begin{tabular}{llll}
\hline Serial number & Organism & Particle size $(\mathbf{n m})$ & Reference \\
\hline 1 & Medicago sativa & 2 to 20 & {$[54]$} \\
2 & Azadirachta indica & 50 & {$[55]$} \\
3 & Aloe vera & 15 to 20 & 55 to 80 \\
4 & Cinnamomum camphora leaf & 15 & {$[56]$} \\
5 & Carica papaya fruit & 50 to 100 & {$[57]$} \\
6 & Cinnamomum zeylanicum bark & 10 to 20 & {$[58]$} \\
7 & Jatropha curcas & 5 to 20 & {$[59]$} \\
8 & Desmodium triflorum & 26 & {$[60]$} \\
9 & Coriandrum sativum leaf & 3 to 37 & {$[61]$} \\
10 & Piper betle leaf & {$[62]$} & {$[63]$} \\
\hline
\end{tabular}

UK Paediatric Burns Centre at Frenchay Hospital in Bristol were working on an advanced bandage that works by releasing antibiotics from nanocapsules triggered by the presence of pathogenic bacteria. The dressing is said to have the potential to change color when the antibiotic is released and hence alerting that there is an infection in the wound. Experts believe that this dressing has great potential in treating burn victims who are susceptible to toxic shock syndrome. With the advent of such system, there can be a reduction in antibiotic resistance [68]. As of 2012, reports suggest that the bandage could be commercialized any time soon. There are newer, efficient, and safer silver nanoparticle-based wound dressings that are being introduced in the market.

Silver nanoparticles are used in bone cements that are used as artificial joint replacements. Polymethyl methacrylate loaded with nanosilver is being considered as bone cement as the nanosilver can induce antimicrobial activity [69]. Ultrahigh molecular weight polyethylene has been the preferred choice for fabricating inserts for total joint replacement components, but it is susceptible to wear and tear which is a major drawback. To overcome this, silver nanoparticles were added, and the presence of silver nanoparticles drastically reduced the wear and tear of the polymer [70]. The currently used methods to prevent surgical infection include antibiotics and antiseptics. Surgical meshes are used to bridge large wounds and for tissue repairs. Though these meshes are effective, they are susceptible to microbial infections. Silver nanoparticlecoated polypropylene mesh is said to have good antimicrobial activity and can be considered an ideal candidate for surgical meshes [71]. The antimicrobial property of silver nanoparticles is documented, and it has immense potential to be used in disinfectants [72]. It is also believed that most medical treatments such as intravenous catheters, endotracheal tubes, wound dressings, bone cements, and dental fillings can all make use of nanosilver to prevent microbial infections.
Nanosilver also has the capacity to be used in biosensing. The plasmonic properties of nanosilver are dictated by its shape, size, and the dielectric medium that surrounds it. Its properties in the dielectric medium that can be exploited make it an ideal candidate for biosensing. Nanosilver biosensors can effectively biosense a large number of proteins that normal biosensors find hard to detect. This unique advantage that nanosilver has can be utilized for detecting various abnormalities and diseases in the human body including cancer [73].

The plasmonic properties of nanosilver also make it an excellent candidate for bioimaging as they, contrary to commonly used fluorescent dyes, do not undergo photobleaching and can be used to monitor dynamic events over an extended period of time [74]. The plasmonic nature of nanosilver can also be used to destroy unwanted cells. The cells can be conjugated to the target cells and then be used to absorb light and convert it to thermal energy; the thermal energy can lead to thermal ablation of the target cells [75].

Studies over the years have proven that it is difficult to remove silver completely if deposited in the body. Animal and human studies have indicated that nanosilver can be excreted through the hair, urine, and feces majorly [76]. However, the main excretion source is biliary excretion. Once orally administered, silver particles pass through the liver, then into the bile, and is excreted out through feces. In the case of inhalation, the particles enter the lungs and subsequently the blood stream and the other organs and are excreted out through urine or feces. The silver particles can enter the body through the skin too from where they enter the blood stream and are taken to various organs and are finally excreted out through urine or feces.

\section{Toxicity of silver nanoparticles}

The unique physical and chemical properties of silver nanoparticles make them excellent candidates for a 
number of day-to-day activities, and also the antimicrobial and anti-inflammatory properties make them excellent candidates for many purposes in the medical field. However, there are studies and reports that suggest that nanosilver can allegedly cause adverse effects on humans as well as the environment.

It is estimated that tonnes of silver are released into the environment from industrial wastes, and it is believed that the toxicity of silver in the environment is majorly due to free silver ions in the aqueous phase. The adverse effects of these free silver ions on humans and all living beings include permanent bluish-gray discoloration of the skin (argyria) or the eyes (argyrosis), and exposure to soluble silver compounds may produce toxic effects like liver and kidney damage; eye, skin, respiratory, and intestinal tract irritations; and untoward changes in blood cells [77].

Since the beginning of the twenty-first century, nanosilver has been gaining popularity and is now being used in almost every field, most importantly the medical field. However, there have been reports of how nanosilver cannot discriminate between different strains of bacteria and can hence destroy microbes beneficial to the ecology [78]. There are only very few studies conducted to assess the toxicity of nanosilver. In one study, in vitro toxicity assay of silver nanoparticles in rat liver cells has shown that even low-level exposure to silver nanoparticles resulted in oxidative stress and impaired mitochondrial function [79]. Silver nanoparticles also proved to be toxic to in vitro mouse germ line stem cells as they impaired mitochondrial function and caused leakage through the cell membranes. Nanosilver aggregates are said to be more cytotoxic than asbestos [80]. There is evidence that shows that silver ions cause changes in the permeability of the cell membrane to potassium and sodium ions at concentrations that do not even limit sodium, potassium, ATP, or mitochondrial activity [81]. The literature also proves that nanosilver can induce toxic effects on the proliferation and cytokine expression by peripheral blood mononuclear cells [66]. Nanosilver is also known to show severe toxic effects on the male reproductive system. Research shows that nanosilver can cross the blood-testes barrier and be deposited in the testes where they adversely affect the sperm cells [82]. Even commercially available silver-based dressings have been proved to have cytotoxic effects on various experimental models [83]. In vivo studies on the oral toxicity of nanosilver on rats have indicated that the target organ in mouse for the nanosilver was the liver. It was also found from histopathological studies that there was a higher incidence of bile duct hyperplasia, with or without necrosis, fibrosis, and pigmentation in the study animals [84]. Studies have also suggested that there is release of silver when the nanoparticles are stored over a period of time. Hence, it has to be said that aged nanosilver is more toxic than new nanosilver [85].

Nanosilver with its antimicrobial activity can hinder the growth of many 'friendly' bacteria in the soil. By showing toxic effects on denitrifying bacteria, silver can disrupt the denitrification process, which involves the conversion of nitrates into nitrogen gas which is essential for the plants. Loss of environmental denitrification through reduction of plant productivity can lead to eutrophication of rivers, lakes, and marine ecosystems and destroy the ecosystem [86]. Nanosilver also has toxic effects on aquatic animals because silver ions can interact with the gills of fish and inhibit basolateral $\mathrm{Na}^{+}-\mathrm{K}^{+}$-ATPase activity, which can in turn inhibit osmoregulation in the fish [87]. To understand the toxic potential nanosilver has on the freshwater environment, the Daphnia magna 48-h immobilization test was conducted, and the results showed that the silver nanoparticles have to be classified under 'category acute 1' as per the Globally Harmonized System of Classification and Labelling of Chemicals, suggesting that the release of nanosilver into the environment has to be carefully considered [88].

Though these studies tend to suggest that nanosilver can induce toxicity to living beings, it has to be understood that the studies on nanosilver toxicity were done in in vitro conditions which are drastically different from in vivo conditions and at quite high concentrations of nanosilver particles. Hence, it is imperative that more studies be carried out to assess the toxicity effect nanosilver has in vivo before a conclusion on its toxicity is reached.

\section{Conclusions}

Silver has always been an excellent antimicrobial and has been used for the purpose for ages. The unique physical and chemical properties of silver nanoparticles only increase the efficacy of silver. Though there are many mechanisms attributed to the antimicrobial activity shown by silver nanoparticles, the actual and most reliable mechanism is not fully understood or cannot be generalized as the nanoparticles are found to act on different organisms in different ways. Chemical and physical methods of silver nanoparticle synthesis were being followed over the decades, but they are found to be expensive and the use of various toxic chemicals for their synthesis makes the biological synthesis the more preferred option. Though bacterial, fungal, and plant extract sources can be used for nanosilver synthesis, the easy availability, the nontoxic nature, the various options available, and the advantage of quicker synthesis make plant extracts the best and an excellent choice for nanosilver synthesis. The uses of silver nanoparticles are varied and many, but the most exploited and desired aspect 
is their antimicrobial capacity and anti-inflammatory capacity. This has been utilized in various processes in the medical field and has hence been exploited well. However, the downside of silver nanoparticles is that they can induce toxicity at various degrees. It is suggested that higher concentrations of silver nanoparticles are toxic and can cause various health problems. There are also studies that prove that nanoparticles of silver can induce various ecological problems and disturb the ecosystem if released into the environment. Hence, care has to be taken to utilize this marvel well and in a good, effective, and efficient way, understanding its limitations and taking extreme care that it does not cause any harm to an individual or the environment. It can be believed that if utilized properly, silver nanoparticles can be a good friend, but if used haphazardly, they can become a mighty foe. Hence, this current review concludes with a hope and prayer that there would be mechanisms devised to nullify any toxicity caused by nanosilver to humans and the environment so that the unique properties of this substance can be put to great use for human betterment without any controversies.

\section{Competing interests}

The authors declare that they have no competing interests.

\section{Authors' contributions}

SP collected all the reprints, understood the concept, and wrote the introduction and conclusion parts under review. EKP wrote the contents and concepts of the remaining subheadings under the guidance of SP. Both authors read and approved the final manuscript.

Received: 2 June 2012 Accepted: 10 October 2012

Published: 29 October 2012

\section{References}

1. Slawson, RM, Trevors, JT, Lee, H: Silver accumulation and resistance in Pseudomonas stutzeri. Arch. Microbiol. 158, 398-404 (1992)

2. Zhao, GJ, Stevens, SE: Multiple parameters for the comprehensive evaluation of the susceptibility of Escherichia coli to the silver ion. Biometals 11, 27-32 (1998)

3. Sondi, I, Salopek-Sondi, B: Silver nanoparticles as antimicrobial agent: a case study on E. coli as a model for Gram-negative bacteria. J. Colloid Interface Sci. 275, 177-182 (2004)

4. Danilcauk, M, Lund, A, Saldo, J, Yamada, H, Michalik, J: Conduction electron spin resonance of small silver particles. Spectrochimaca. Acta. Part A. 63, 189-191 (2006)

5. Kim, JS, Kuk, E, Yu, K, Kim, JH, Park, SJ, Lee, HJ, Kim, SH, Park, YK, Park, YH, Hwang, C-Y, Kim, YK, Lee, YS, Jeong, DH, Cho, MH: Antimicrobial effects of silver nanoparticles. Nanomedicine 3, 95-101 (2007)

6. Feng, QL, Wu, J, Chen, GQ, Cui, FZ, Kim, TN, Kim, JO: A mechanistic study of the antibacterial effect of silver ions on Escherichia coli and Staphylococcus aureus. J. Biomed. Mater. Res. 52, 662-668 (2008)

7. Matsumura, Y, Yoshikata, K, Kunisaki, S, Tsuchido, T: Mode of bacterial action of silver zeolite and its comparison with that of silver nitrate. Appl. Environ. Microbiol. 69, 4278-4281 (2003)

8. Morones, JR, Elechiguerra, JL, Camacho, A, Holt, K, Kouri, JB, Ramirez, JT, Yacaman, MJ: The bactericidal effect of silver nanoparticles. Nanotechnology 16, 2346-2353 (2005)

9. Hatchett, DW, Henry, S: Electrochemistry of sulfur adlayers on low-index faces of silver. J. Phys. Chem. 100, 9854-9859 (1996)

10. Shrivastava, S, Bera, T, Roy, A, Singh, G, Ramachandrarao, P, Dash, D: Characterisation of enhanced antibacterial effects of novel silver nanoparticles. Nanotechnology 18, 1-9 (2007)
11. Gaffet, E, Tachikart, M, El Kedim, O, Rahouadj, R: Nanostructural materials formation by mechanical alloying: morphologic analysis based on transmission and scanning electron microscopic observations. Mater. Charact 36, 185-190 (1996)

12. Amulyavichus, A, Daugvila, A, Davidonis, R, Sipavichus, C: Study of chemical composition of nanostructural materials prepared by laser cutting of metals. Fizika Met. Met. 85, 111-117 (1998)

13. Thirumalai Arasu, V, Prabhu, D, Soniya, M: Stable silver nanoparticle synthesizing methods and its applications. J. Bio. Sci. Res. 1, 259-270 (2010)

14. $\mathrm{Zhu}, \mathrm{J}, \mathrm{Liao}, \mathrm{X}, \mathrm{Chen}, \mathrm{H}-\mathrm{Y}$ : Electrochemical preparation of silver dendrites in the presence of DNA. Mater. Res. Bull. 36, 1687-1692 (2001)

15. Salkar, RA, Jeevanandam, P, Aruna, ST, Koltypin, Y, Gedanken, A: The sonochemical preparation of amorphous silver nanoparticles. J. Mater. Chem. 9, 1333-1335 (1999)

16. Mandal, S, Arumugam, S, Pasricha, R, Sastry, M: Silver nanoparticles of variable morphology synthesized in aqueous foams as novel templates. Bull. Mater. Sci. 28, 503-510 (2001)

17. Jiang, $\mathrm{H}$, Moon, $\mathrm{K}$, Zhang, Z, Pothukuchi, S, Wong, CP: Variable frequency microwave synthesis of silver nanoparticles. J. Nanopart. Res. 8, 117-124 (2006)

18. Esumi, $K$, Tano, $T$, Torique, $K$, Meguro, K: Preparation and characterization of bimetallic $\mathrm{Pd}-\mathrm{Cu}$ colloids by thermal decomposition of their acetate compounds in organic solvents. Chem. Mater. 2, 564-56 (1990)

19. Pileni, MP: Fabrication and physical properties of self-organized silver nanocrystals. Pure Appl. Chem. 72, 53-65 (2000)

20. Sun, YP, Atorngitjawat, P, Meziani, MJ: Preparation of silver nanoparticles via rapid expansion of water in carbon dioxide microemulsion into reductant solution. Langmuir 17, 5707-5710 (2001)

21. Tien, DC, Tseng, KH, Liao, CY, Tsung, TT: Colloidal silver fabrication using the spark discharge system and its antimicrobial effect on Staphylococcus aureus. Med. Eng. Phys. 30, 948-952 (2007)

22. Sergeev, MB, Kasaikin, AV, Litmanovich, AE: Cryochemical synthesis and properties of silver nanoparticle dispersions stabilised by poly(2dimethylaminoethyl methacrylate). Mendeleev. Commun. 9, 130-132 (1999)

23. Kalishwaralal, K, Deepak, V, Ramkumarpandian, S, Nellaiah, H, Sangiliyandi, G: Extracellular biosynthesis of silver nanoparticles by the culture supernatant of Bacillus licheniformis. Mater. Lett. 62, 4411-4413 (2008)

24. Parashar, UK, Saxena, SP, Srivastava, A: Bioinspired synthesis of silver nanoparticles. Dig. J. Nanomat. Biostruct. 4, 159-166 (2009)

25. Haefeli, C, Franklin, C, Hardy, K: Plasmid-determined silver resistance in Pseudomonas stutzeri isolated from a silver mine. J. Bacteriol. 158, 389-392 (1984)

26. Husseiny, MI, Aziz, MAE, Badr, Y, Mahmoud, MA: Biosynthesis of gold nanoparticles using Pseudomonas aeruginosa. Spectrochimica. Acta. Part A. 67, 1003-1006 (2006)

27. Vaidyanathan, R, Gopalram, S, Kalishwaralal, K, Deepak, V, Pandian, SR, Gurunathan, S: Enhanced silver nanoparticle synthesis by optimization of nitrate reductase activity. Colloids Surf. B Biointerfaces 75, 335-341 (2010)

28. Anil Kumar, S, Majid, KA, Gosavi, SW, Kulkarni, SK, Pasricha, R, Ahmad, A, Khan, MI: Nitrate reductase mediated synthesis of silver nanoparticles from $\mathrm{AgNO}_{3}$. Biotechnol. Lett. 29, 439-445 (2007)

29. Fu, JK, Liu, Y, Gu, P, Tang, DL, Lin, ZY, Yao, BX, Weng, S: Spectroscopic characterization on the biosorption and bioreduction of $\mathrm{Ag}(\mathrm{I})$ by Lactobacillus sp. A09. Acta. Physico-Chimica. Sinica. 16, 770-782 (2000)

30. Tanja, K, Ralph, J, Eva, O, Claes-Göran, G: Silver-based crystalline nanoparticles, microbially fabricated. PNAS 96, 13611-13614 (1999)

31. Fu, JK, Zhang, WD, Liu, YY, Lin, ZY, Yao, BX, Weng, SZ, Zeng, JL: Characterization of adsorption and reduction of noble metal ions by bacteria. Chem. J. Chin. Univ. 20, 1452-1454 (1999)

32. Lengke, FM, Fleet, EM, Southam, G: Biosynthesis of silver nanoparticles by filamentous cyanobacteria a from a silver(I) nitrate complex. Langmuir 23 , 2694-2699 (2007)

33. Minaeian, S, Shahverdi, RA, Nohi, SA, Shahverdi, RH: Extracellular biosynthesis of silver nanoparticles by some bacteria. J. Sci. I. A. U. 17(66), 1-4 (2008)

34. El-Shanshoury, AER, ElSilk, SE, Ebeid, ME: Extracellular biosynthesis of silver nanoparticles using Escherichia coli ATCC 8739, Bacillus subtilis ATCC 6633, and Streptococcus thermophilus ESh1 and their antimicrobial activities. ISRN Nanotechnology 2011, 1-7 (2011)

35. Kalimuthu, K, Babu, RS, Venkataraman, D, Bilal, M, Gurunathan, S: Biosynthesis of silver nanocrystals by Bacillus licheniformis. Colloids Surf. B Biointerfaces 65, 150-153 (2008) 
36. Sintubin, L, De Windt, W, Dick, J, Mast, J, van der Ha, D, Verstraete, W, Boon, $\mathrm{N}$ : Lactic acid bacteria as reducing and capping agent for the fast and efficient production of silver nanoparticles. Appl. Microbiol. Biotechnol. 84, 741-749 (2009)

37. Mokhtari, M, Deneshpojouh, S, Seyedbagheri, S, Atashdehghan, R, Abdi, K, Sarkar, S, Minaian, S, Shahverdi, RH, Shahverdi, RA: Biological synthesis of very small silver nanoparticles by culture supernatant of Klebsiella pneumonia: the effects of visible-light irradiation and the liquid mixing process. Mater. Res. Bull. 44, 1415-1421 (2009)

38. Samadi, N, Golkaran, D, Eslamifar, A, Jamalifar, H, Fazeli, MR, Mohseni, FA: Intra/extracellular biosynthesis of silver nanoparticles by an autochthonous strain of Proteus mirabilis isolated from photographic waste. J. Biomed. Nanotechnol. 5, 247-253 (2009)

39. Kalishwaralal, K, Deepak, V, Pandiana, SBRK, Kottaisamy, M, BarathManiKanth, S, Kartikeyan, B, Gurunathan, S: Biosynthesis of silver and gold nanoparticles using Brevibacterium casei. Colloids Surf. B Biointerfaces 77, 257-262 (2010)

40. Mohanpuria, P, Rana, KN, Yadav, SK: Biosynthesis of nanoparticles: technological concepts and future applications. J. Nanopart. Res. 10, 507-517 (2008)

41. Mukherjee, P, Ahmad, A, Mandal, D, Senapati, S, Sainkar, SR, Khan, MI, Parischa, R, Ajaykumar, PV, Alam, M, Kumar, R, Sastry, M: Fungus mediated synthesis of silver nanoparticles and their immobilization in the mycelial matrix: a novel biological approach to nanoparticle synthesis. Nano Lett. 1, 515-519 (2001)

42. Ahmad, A, Mukherjee, P, Senapati, S, Mandal, D, Khan, MI, Kumar, R, Sastry, M: Extracellular biosynthesis of silver nanoparticles using the fungus Fusarium oxysporum. Colloids Surf. B Biointerfaces 28, 313-318 (2003)

43. Mukherjee, P, Ahmad, A, Mandal, D, Senapati, S, Sainkar, SR, Khan, MI, Ramani, R, Parischa, R, Ajayakumar, PV, Alam, M, Sastry, M, Kumar, R: Bioreduction of $\mathrm{AuCl}^{4-}$ ions by the fungus, Verticillium sp. and surface trapping of the gold nanoparticles formed. Angew. Chem. Int. Ed 40, 3585-3588 (2001)

44. Chen, JC, Lin, ZH, Ma, XX: Evidence of the production of silver nanoparticles via pretreatment of Phoma sp. 3.2883 with silver nitrate. Lett. Appl. Microbiol. 37, 105-108 (2003)

45. Duran, N, Marcato, DP, Alves, LO, De Souza, G, Esposito, E: Mechanical aspect of biosynthesis of silver nanoparticles by several Fusarium oxysporum strains. J. Nanobiotechnology 3, 8-15 (2005)

46. Vigneshwaran, N, Kathe, AA, Varadarajan, PV, Nachane, RP, Balasubramanya, $\mathrm{RH}$ : Biomimetics of silver nanoparticles by white rot fungus, Phaenerochaete chrysosporium. Colloids Surf. B Biointerfaces 53, 55-59 (2006)

47. Bhainsa, CK, D'Souza, FS: Extracellular biosynthesis of silver nanoparticles using the fungus Aspergillus funigatus. Colloids Surf. B Biointerfaces 47, 160-164 (2006)

48. Vigneshwaran, N, Ashtaputre, NM, Varadarajan, PV, Nachane, RP, Paralikar, KM, Balasubramanya, RH: Biological synthesis of silver nanoparticles using the fungus Aspergillus flavus. Mater. Lett. 66, 1413-1418 (2007)

49. Basavaraja, S, Balaji, SD, Lagashetty, A, Rajasabd, AH, Venkataraman, A: Extracellular biosynthesis of silver nanoparticles using the fungus Fusarium semitectum. Mater. Res. Bull 43, 1164-1170 (2008)

50. Sanghi, R, Verma, P: Biomimetic synthesis and characterisation of protein capped silver nanoparticles. Bioresour. Technol. 100, 501-504 (2009)

51. Gade, A, Ingle, A, Bawaskar, M, Rai, M: Fusarium solani: a novel biological agent for extracellular synthesis of nanoparticles. J. Nanopart. Res. 11, 2079-2085 (2009)

52. Verma, VC, Kharwar, RN, Gange, AC: Biosynthesis of antimicrobial silver nanoparticles by the endophytic fungus Aspergillus clavatus. Nanomedicine 5, 33-40 (2010)

53. Jha, AK, Prasad, K, Prasad, K, Kulkarni, AR: Plant system: nature's nanofactory. Colloids Surf. B Biointerfaces 73, 219-223 (2009)

54. Gardea-Torresdey, JL, Gomez, E, Peralta-Videa, JR, Parsons, JG, Troiani, H, Jose-Yacaman, M: Alfalfa sprouts: a natural source for the synthesis of silver nanoparticles. Langmuir 19, 1357-1361 (2003)

55. Shankar, SS, Rai, A, Ahmad, A, Sastry, M: Rapid synthesis of Au, Ag, and bimetallic Au core-Ag shell nanoparticles using Neem (Azadirachta indica) leaf broth. J. Colloid Interface Sci. 275, 496-502 (2004)

56. Chandran, SP, Chaudhary, M, Pasricha, R, Ahmad, A, Sastry, M: Synthesis of gold nanotriangles and silver nanoparticles using Aloe vera plant extract. Biotechnol. Prog. 22, 577-583 (2006)

57. Huang, J, Li, Q, Sun, D, Lu, Y, Su, Y, Yang, X, Wang, H, Wang, Y, Shao, W, He, $\mathrm{N}$ : Biosynthesis of silver and gold nanoparticles by novel sundried Cinnamomum camphora leaf. Nanotechnol. 18, 1-11 (2007)
58. Jain, D, Kumar Daima, H, Kachhwaha, S, Kothari, SL: Synthesis of plantmediated silver nanoparticles using papaya fruit extract and evaluation of their anti microbial activities. Digest Journal of Nanomaterials and Biostructures 4, 557-563 (2009)

59. Sathishkumar, M, Sneha, K, Won, SW, Cho, C-W, Kim, S, Yun, Y-S: Cinnamon zeylanicum bark extract and powder mediated green synthesis of nanocrystalline silver particles and its bactericidal activity. Colloids Surf. B Biointerfaces 73, 332-338 (2009)

60. Bar, H, Bhui, KD, Sahoo, PG, Sarkar, P, De, PS, Misra, A: Green synthesis of silver nanoparticles using latex of Jatropha curcas. Colloids Surf. A Physicochem. Eng. Asp. 339, 134-139 (2009)

61. Ahmad, N, Sharma, S, Singh, VN, Shamsi, SF, Fatma, A, Mehta, BR: Biosynthesis of silver nanoparticles from Desmodium triflorum: a novel approach towards weed utilization. Biotechnology Research International 2011, 1-8 (2011). doi:10.4061/2011/454090

62. Sathyavathi, R, Krishna, MB, Rao, SV, Saritha, R, Rao, DN: Biosynthesis of silver nanoparticles using Coriandrum sativum leaf extract and their application in nonlinear optics. Adv. Sci. Lett. 3, 138-143 (2010)

63. Mallikarjuna, K, Dillip, GR, Narasimha, G, John Sushma, N, Deva Prasad Raju, $B$ : Phytofabrication and characterization of silver nanoparticles from Piper betle broth. Res. J. Nanosci. Nanotechnol. 2, 17-23 (2012)

64. Kirsner, R, Orsted, H, Wright, B: Matrix metalloproteinases in normal and impaired wound healing: a potential role of nanocrystalline silver. Wounds 13, 5-10 (2001)

65. Tian, J, Wong, KK, Ho, CM, Lok, CN, Yu, WY, Che, CM, Chiu, JF, Tam, PK: Tropical delivery of silver nanoparticles promotes wound healing. Chem. Med. Chem. 2, 129-136 (2007)

66. Shin, SH, Ye, MK, Kim, HS, Kang, HS: The effects of nano-silver on the proliferation and cytokine expression by peripheral blood mononuclear cells. Int. Immunopharmacol. 7, 1813-1818 (2007)

67. Burrell, RE, McIntosh, CL, Morris, LR: Process of activating anti-microbial materials. Patent 5454886, 3 (1995)

68. Nano Bio Technology: Revolutionary medical bandage using nanotechnology to fight infection. http://nanobiotechnews.com/ revolutionary-medical-bandage-using-nanotechnology-to-fight-infection. html (2010). Accessed 15 Sept 2012

69. Alt, V, Bechert, T, Steinrücke, P, Wagener, M, Seidel, P, Dingeldein, E, Scheddin, D, Domann, E, Schnettler, R: Nanoparticulate silver. A new antimicrobial substance for bone cement. Orthopade 33, 885-892 (2004)

70. Morley, KS, Webb, PB, Tokareva, NV, Krasnov, AP, Popov, VK, Zhang, J, Roberts, CJ, Howdle, SM: Synthesis and characterisation of advanced UHMWPE/silver nanocomposites for biomedical applications. Eur. Polym. J. 43, 307-314 (2007)

71. Cohen, MS, Stern, JM, Vanni, AJ, Kelley, RS, Baumgart, E, Field, D, Libertino, JA, Summerhayes, IC: In vitro analysis of a nanocrystalline silver-coated surgical mesh. Surg. Infect. 8, 397-403 (2007)

72. Brady, MJ, Lissay, CM, Yurkovetskiy, AV, Sarwan, SP: Persistent silver disinfectant for environmental control of pathogenic bacteria. Am. J. Infect. Control 31, 208-214 (2003)

73. Zhou, W, Ma, YY, Yang, HA, Ding, Y, Luo, XG: A label-free biosensor based on silver nanoparticles array for clinical detection of serum p53 in head and neck squamous cell carcinoma. Int. J. Nanomed. 6, 381-386 (2011)

74. Lee, KJ, Nallathamby, PD, Browning, LM, Osgood, CJ, Xu, XHN: In vivo imaging of transport and biocompatibility of single silver nanoparticles in early development of zebra fish embryos. ACS Nano 1, 133-143 (2007)

75. Loo, C, Lowery, A, Halas, N, West, J, Drezek, R: Immunotargeted nanoshells for integrated cancer imaging and therapy. Nano Lett. 5, 709-711 (2005)

76. Di Vincenzo, GD, Giordano, CJ, Schriever, LS: Biologic monitoring of workers exposed to silver. Int. Arch. Occup. Environ. Health 56, 207-215 (1985)

77. Panyala, NR, Pena-Mendez, EM, Havel, J: Silver or silver nanoparticles: a hazardous threat to the environment and human health? J. Appl. Biomed. 6, 117-129 (2008)

78. Allsopp, M, Walters, A, Santillo, D: Nanotechnologies and Nanomaterials in Electrical and Electronic Goods: A Review of Uses and Health Concerns. Greenpeace Research Laboratories, London (2007)

79. Hussain, SM, Hess, KL, Gearhart, JM, Geiss, KT, Schlager, JJ: In vitro toxicity of nanoparticles in BRL 3A rat liver cells. Toxicol. In Vitro 19, 975-983 (2005)

80. Soto, KF, Murr, LE, Garza, KM: Cytotoxic responses and potential respiratory health effects of carbon and carbonaceous nanoparticulates in the Paso del Norte airshed environment. Int. J. Environ. Res. Public Health 5, 12-25 (2008) 
81. Kone, $\mathrm{BC}$, Kaleta, $\mathrm{M}$, Gullans, SR: Silver ion $\left(\mathrm{Ag}^{+}\right)$-induced increases in cell membrane $\mathrm{K}^{+}$and $\mathrm{Na}^{+}$permeability in the renal proximal tubule: reversal by thiol reagents. J. Membr. Biol. 102, 11-19 (1988)

82. McAuliffe, ME, Perry, MJ: Are nanoparticles potential male reproductive toxicants? A literature review. Nanotoxicol 1, 204-210 (2007)

83. Burd, A, Kwok, CH, Hung, SC, Chan, HS, Gu, H, Lam, WK, Huang, L: A comparative study of the cytotoxicity of silver-based dressings in monolayer cell, tissue explant, and animal models. Wound. Rep. Reg. 15, 94-104 (2007)

84. Kim, YS, Song, MY, Park, JD, Song, KS, Ryu, HR, Chung, YH, Chang, HK, Lee, $\mathrm{JH}, \mathrm{Oh}, \mathrm{KH}$, Kelman, BJ, Hwang, IK, Yu, IJ: Subchronic oral toxicity of silver nanoparticles. Part. Fibre Toxicol. 7, 20 (2010)

85. Kittler, S, Greulich, C, Diendorf, J, Köller, M, Epple, M: Toxicity of silver nanoparticles increases during storage because of slow dissolution under release of silver ions. Chem. Mater. 22, 4548-4554 (2010)

86. Senjen, R: Nanosilver - a threat to soil, water and human health? Friends of the Earth Australia. http://nano.foe.org.au/sites/default/files/Nanosilver\%20-\% 20a\%20threat\%20to\%20soil,\%20water\%20and\%20health\%20March\%202007. pdf (2007). Accessed 17 May 2012

87. Wood, CM, Playle, RC, Hogstrand, C: Physiology and modeling of mechanisms of silver uptake and toxicity in fish. Environ. Toxicol. Chem. 18, 71-83 (1993)

88. Asghari, S, Johari, SA, Lee, JH, Kim, YS, Jeon, YB, Choi, HJ, Moon, MC, Yu, IJ: Toxicity of various silver nanoparticles compared to silver ions in Daphnia magna. J. Nanobiotechnology 10, 14 (2012)

doi:10.1186/2228-5326-2-32

Cite this article as: Prabhu and Poulose: Silver nanoparticles: mechanism of antimicrobial action, synthesis, medical applications, and toxicity effects. International Nano Letters 2012 2:32.

\section{Submit your manuscript to a SpringerOpen ${ }^{\circ}$ journal and benefit from:}

- Convenient online submission

- Rigorous peer review

- Immediate publication on acceptance

- Open access: articles freely available online

- High visibility within the field

- Retaining the copyright to your article 